\title{
Durability of Concrete Containing PFA-GGBS By-products
}

\author{
J.E. Oti ${ }^{1, *}$, J.M. Kinuthia ${ }^{1}$, B.O. Adeleke ${ }^{1}$, N. Billong ${ }^{2}$ \\ 1. School of Engineering, Faculty of Computing, Engineering and Science, University of South Wales, \\ Pontypridd, CF37 1DL, UK \\ 2. Materials Analysis Laboratory, MIPROMALO, P.O. Box 2396, Yaoundé, Cameroon \\ E-mail: jonathan.oti@southwales.ac.uk (Corresponding author)
}

Received: 7 July 2020; Accepted: 24 July 2020; Available online: 15 August 2020

\begin{abstract}
Ground Granulated Blast-furnace Slag (GGBS) and Pulverised Fuel Ash (PFA) were used to replace up to $60 \%$ of Portland cement (PC) in concrete. The testing program of the concrete included the determination of the consistency of fresh concrete, the measurement of the density and compressive strength of the hardened products cured for up to 56 days and the evaluation of their durability via visual inspections and strength loss calculations after the freeze and thaw cycles. The results showed that the blend proportion and type had affected the consistency of the fresh concrete. Replacing the PC with $20 \%$ for PFA or $40 \%$ for GGBS had similar performances as the control mix. The durability of concrete subject to freeze and thaw had little effect on the concrete specimens. It was observed that the concrete without blends suffered the worst, resulting in chips along the edges of the cube and scaling of the faces compared to mixes with 20\% GGBS and 20\% PFA which resulted in increased durability. However, blended concrete exhibited more loss in strength compared to the concrete without cement blends.
\end{abstract}

Keywords: Sustainable concrete; Binder materials; Mechanical strength; Freezing and thawing; XRD analysis; Thermogravimetric and derivative analysis.

\section{Introduction}

According to the World Business Council for Sustainable Development, approximately 5-7\% of man-made global $\mathrm{CO}_{2}$ emissions come from the production of Portland cement. The production of cement is set to continue increasing as demand worldwide is continuing to increase, especially where emerging economies need cement for housing and infrastructure [1]. Due to increased regulations to reduce the carbon footprint of the construction industry, to limit greenhouse gas emission and to better management of landfill spaces, the search for the optimal re-use of industrial by-products in cement and concrete has been conducted for several decades with relative satisfactory results [2].Some industrial by-products are being piled into open landfill sites causing contamination and rendering the sites obsolete for many years. The waste by-products play the role of either supplementary cementing materials (SCM) or alternative aggregate (AA). Construction cost and technical barriers such as insufficient durability data and differentiation for different applications are still hindering the global promotion of concrete utilizing high amounts of industrial by-product additives [2-4]. Waste material by-products such as Pulverised Fuel Ash (PFA) and Ground Granulated Blast-furnace Slag (GGBS) as partial replacements of Portland cement (PC) have been in use since the mid-1950s and interest in these materials has been increasing in recent years [5-7].

The overall aim of the current work is to contribute to the availability of engineering data on concrete containing PFA and GGBS, especially in areas with extreme weather conditions such as freezing temperatures, with only a little sunlight providing heat sporadically. This work reports on the effect of PFA or GGBS on the consistency of fresh concrete and freezing-thawing performance of the concrete. In addition, the mechanical performance of the concrete produced from 20-60\% PFA or GGBS were also evaluated. This 20-60\% PFA or GGBS were used to replace PC to reduce the carbon footprint of the concrete, utilising high amounts of industrial by-product additives and at the same time producing a workable concrete.

\section{Methodology}

\subsection{Materials}

Pulverised Fuel Ash (PFA) used was in compliance with BS EN 450-1:2012 [8]. PFA is a by-product from coal-fired powered stations and is produced when pulverised coal is fed into the boilers and burnt at very high 
temperature of about $1400^{\circ} \mathrm{C}$. Ground Granulated Blast-furnace Slag (GGBS) was in compliance with BS EN 15167-1:2006 [9], it is a by-product material, generated from the iron-making industry. The Portland Cement (PC), was manufactured in accordance with BS EN 197-1:2011 [10]. A local contractor supplied the PFA, GGBS and PC used throughout this research; their oxide compositions and some physical properties can be seen in Table 1. Limestone aggregate of size $10 \mathrm{~mm}$ and natural sea-dredged sand from the Bristol Channel supplied by a local quarry and complied with the requirements of BS EN 12620:2002+A1:2008 [11] were also used throughout. Some geometrical, mechanical and physical properties of the aggregates can be seen in Oti and Kinuthia [12].

Table 1. The oxide composition and some physical properties of PC, GGBS and PFA.

\begin{tabular}{llll}
\hline & PC (\%) & GGBS (\%) & PFA (\%) \\
\hline Oxide & & & \\
Lime $(\mathrm{CaO})$ & 60 & 42 & 0.22 \\
Silicon Dioxide $\left(\mathrm{SiO}_{2}\right)$ & 20 & 35.35 & $59 \cdot 04$ \\
Aluminium Oxide $\left(\mathrm{Al}_{2} \mathrm{O}_{3}\right)$ & 6 & 11.6 & 34.08 \\
Magnesium Oxide $(\mathrm{MgO})$ & 4.21 & 8 & 0.43 \\
Iron Oxide $\left(\mathrm{Fe}_{2} \mathrm{O}_{3}\right)$ & 3 & 0.35 & 2.00 \\
Manganese Oxide $(\mathrm{MnO})$ & $0.03-1.11$ & 0.45 & - \\
Sulphide $\left(\mathrm{S}_{2}\right)$ & - & 1.2 & - \\
Sulphur Trioxide $\left(\mathrm{SO}_{3}\right)$ & 2.3 & 0.23 & 0.05 \\
Alkalis $\left(\mathrm{Na} 2 \mathrm{O}, \mathrm{K}_{2} \mathrm{O}\right)$ & - & - & 1.26 \\
Loss on ignition & 0.8 & $1-3$ & 0.6 \\
\hline Properties & & \multicolumn{2}{l}{} \\
Insoluble Residue & 0.5 & 0.3 & 80.4 \\
Bulk Density $\left(\mathrm{kg} / \mathrm{m}^{3}\right)$ & 1400 & 1200 & 2.29 \\
Specific Gravity & 3.15 & 2.9 & $500-650$ \\
Blaine fineness $\left(\mathrm{m}^{2} / \mathrm{kg}\right)$ & 365 & 450 & light Grey \\
Colour & Grey & Off White & $\approx 80$ \\
Glass Content & - & $\approx 90$ & \\
\hline
\end{tabular}

* Notation: PC = Portland Cement; GGBS = Ground Granulated Blast-furnace Slag; PFA = Pulverised Fuel Ash

\subsection{Mix design}

The control mix in this research used a binder: sand: aggregate ratio of 1: 2: 3, with Portland Cement content of $500 \mathrm{~kg} / \mathrm{m}^{3}$ and water/binder ratio of 0.55 , typically classed as C30 concrete. The control mix is labelled as $100 \mathrm{PC}$. To investigate the potential to partially replace PC in concrete, up to $60 \%$ of the cement in the control mix was replaced with GGBS or PFA, in various combinations as shown in Table 2. In the second, third, fourth, fifth, sixth and seventh mixes, 80PC-20GGBS, 60PC-40GGBS, 40PC-60GGBS, 80PC-20PFA, 60PC-40PFA and 40PC60PFA respectively (see Table 2 for details), the PC in the control mix was partially replaced with 20-60\% GGBS or PFA.

Table 2. Mix Composition

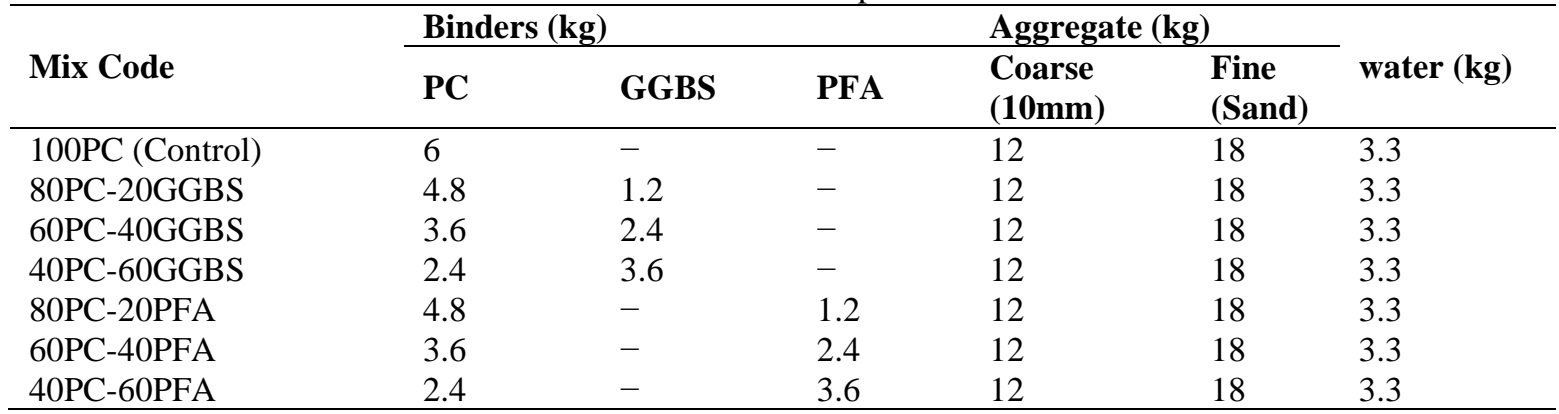

\subsection{Test specimen preparation and testing}

X-ray diffraction (XRD) analysis was carried out on the raw binder samples (PC, GGBS and PFA), XRD is one of the most prominently applied analytical techniques in the identification and quantification of mineralogical compounds of fine-grained crystalline materials. It was carried out under room temperature using a STOE Powder Diffraction System with operating conditions of $\mathrm{CuK} \alpha$ sealed tube (Figure 1), which shows the minor crystalline phases (anhydrite, gypsum, portlandite, lime and calcite) and the glassy (amorphous) phase of GGBS and PFA. This was operated at radiation of $1.54060 \mathrm{~nm}$ with a measurement range from 10 to $80^{\circ} 2 \Theta$ at $0.015^{0}$ step according to ASTM C1365 - 18 [13]. It was conducted to analyse the thermal stability, oxidative stability, decomposition 
kinetics of the materials by analysing the curve of weight loss/gain vs the increase of temperature. Thermal analysis (both thermogravimetric and derivative thermogravimetric analyses (TG/DTG)) for the materials was performed using a TA instruments TGA55 kit associated with a TRIOS computer software. The analysis was performed to aid in the interpretation of the possible reaction mechanisms behind the variations in the engineering properties of the concrete test specimens. The TG/DTG was performed by testing the dry sample mixtures in aluminium crucibles, under an argon gas atmosphere at a heating rate of $10^{\circ} \mathrm{C} / \mathrm{min}$ up to $1000^{\circ} \mathrm{C}$ using a Hi-Res TGA55 TA instruments thermal apparatus [13]. Standard dimension of a cube $(100 \mathrm{~mm} \times 100 \mathrm{~mm} \times 100 \mathrm{~mm})$ and standard dimension of a cylinder $(150 \mathrm{~mm} \times 300 \mathrm{~mm})$ test specimens were used in the production of the concrete. For all mix compositions, the test specimens, were prepared in accordance with BS EN 206:2013+A1:2016 [14]. The consistency of the fresh concrete was measured using slump and compaction index test in accordance with BS EN 12350-2:2019 [15] and BS EN 12350-4:2019 [16] respectively. De-moulding of the test specimens was done after 24 hours. The curing of the test specimens was carried out in accordance with BS EN 12390-2:2019 [17]. All the cube specimens were tested for 7, 28 and 56-day compressive strength in accordance with BS EN 12390-3:2019 [17]. The concrete cylinders were tested for 28-day tensile splitting strength in accordance with BS EN 12390-6:2009 [18]. For all mix compositions, the results reported are the average obtained from five individual specimens for compressive strength and three for tensile splitting strength. The durability assessment of the concrete in a severe environment was carried out in a Prior Clave $\mathrm{LCH} / 600 / 25$ model $0.7 \mathrm{~m}^{3}$ volume capacity environmental chamber, in compliance with PD CEN/TS 12390-9:2016 [19]. The specimens were left in the freezing chamber for seven days at a temperature of $-17^{\circ} \mathrm{C}$ and then thawed for one hour in a temperaturecontrolled water bath set at $[20 \pm 2]^{\circ} \mathrm{C}$. The freezing and thawing cycles were repeated eight times and the weight losses of the concrete specimens were recorded. A visual inspection was undertaken to record any scaling, spalling, cracking or chipping that occurred to any of the concretes.

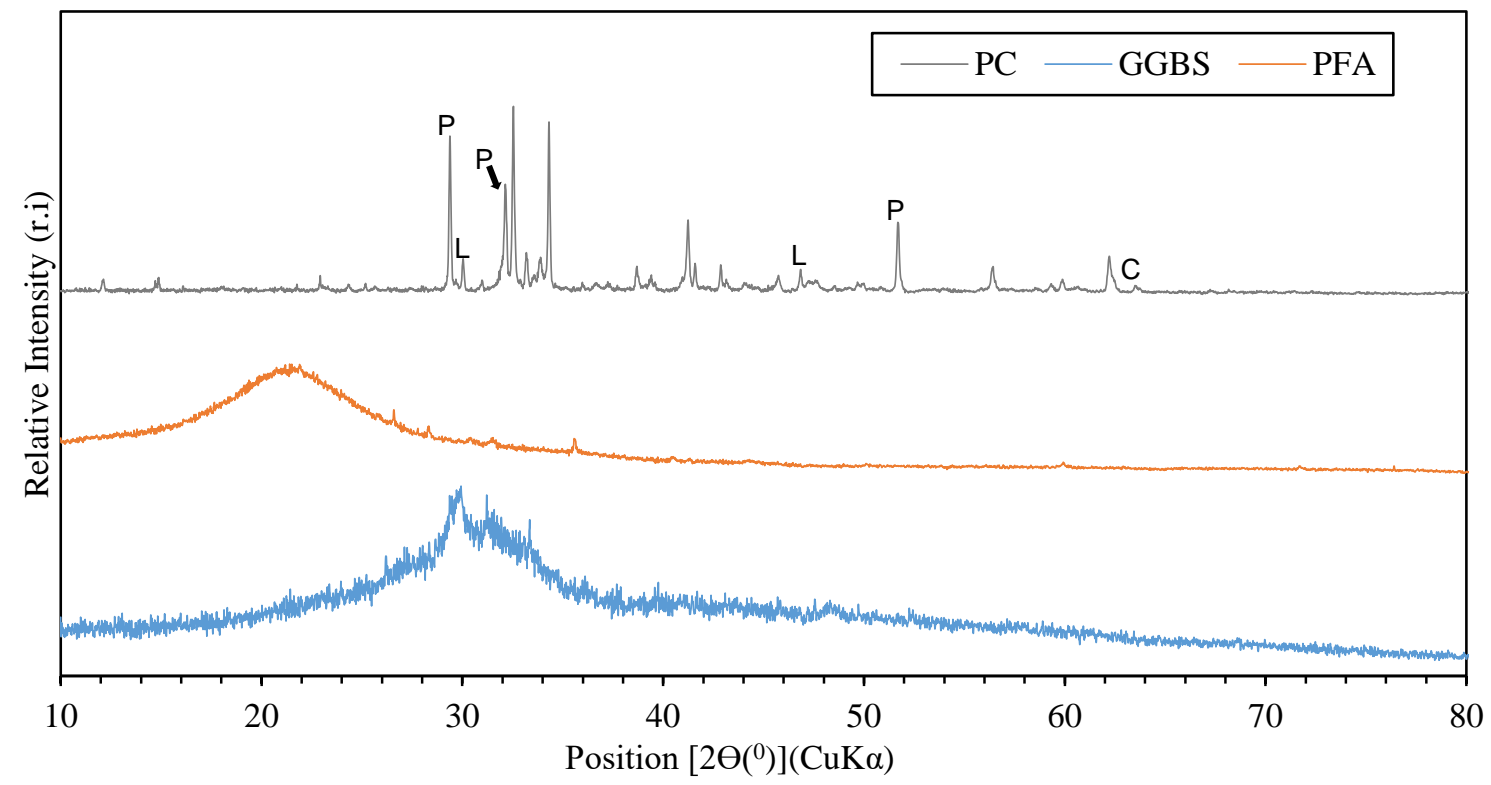

Figure 1. XRD result patterns for raw binder materials. (A - Anhydrite [CaSO 4 ], G - Gypsum $\left[\mathrm{CaSO}_{4} .2 \mathrm{H}_{2} \mathrm{O}\right], \mathrm{P}_{-}$ Portlandite $\mathrm{Ca}(\mathrm{OH})_{2}, \mathrm{C}-\mathrm{CaO}, \mathrm{L}-$ Calcite $\left[\mathrm{CaCO}_{3}\right]$ )

\section{Results and Discussion}

\subsection{Thermal analysis of binders}

Figures 2 and 3 show the thermogravimetric and derivative thermogravimetric analysis (TG/DTG) results for all the mixes, which was carried out to a maximum temperature of $1000^{\circ} \mathrm{C}$. Four endothermic DTG peaks were observed at points 1, 2, 3, 4 and 5 for all the mixes, representing their crystalline/amorphous hydration phases with varying peak heights at temperature ranges of $20-80^{\circ} \mathrm{C} ; 100-120^{\circ} \mathrm{C} ; 420-480^{\circ} \mathrm{C}$ and $700-800^{\circ} \mathrm{C}$ respectively. Observation shows that the control mix (100PC) attained the highest endothermic DTG peak for every location (1, 2, 3, 4 and 5) with a gradual reduction in peak heights in the order 80PC-20GGBS, 80PC-20PFA, 60PC-40PFA, 60PC-40GGBS, 40PC-60PFA and 40PC-60GGBS respectively. It is worthy to note that the observed weight losses between 0 and $600^{\circ} \mathrm{C}$ are attributed to water loss, while above $600^{\circ} \mathrm{C}$ are losses primarily associated with the release of carbon dioxide or decarboxylation [20]. The observed peaks at point 1 could be attributed to the loss of water due to the dehydration of loosely bound hydroxyl group in the binder mixes [21], while peak 2 and 3 is 
suggested to be the decomposition phases of gypsum within each mix proportion at different forms of calcium sulphate dihydrate $\left(\mathrm{CaSO}_{4} \cdot 2 \mathrm{H}_{2} \mathrm{O}\right)$ to calcium sulphate anhydrite $\left(\mathrm{CaSO}_{4}\right)$ [22].

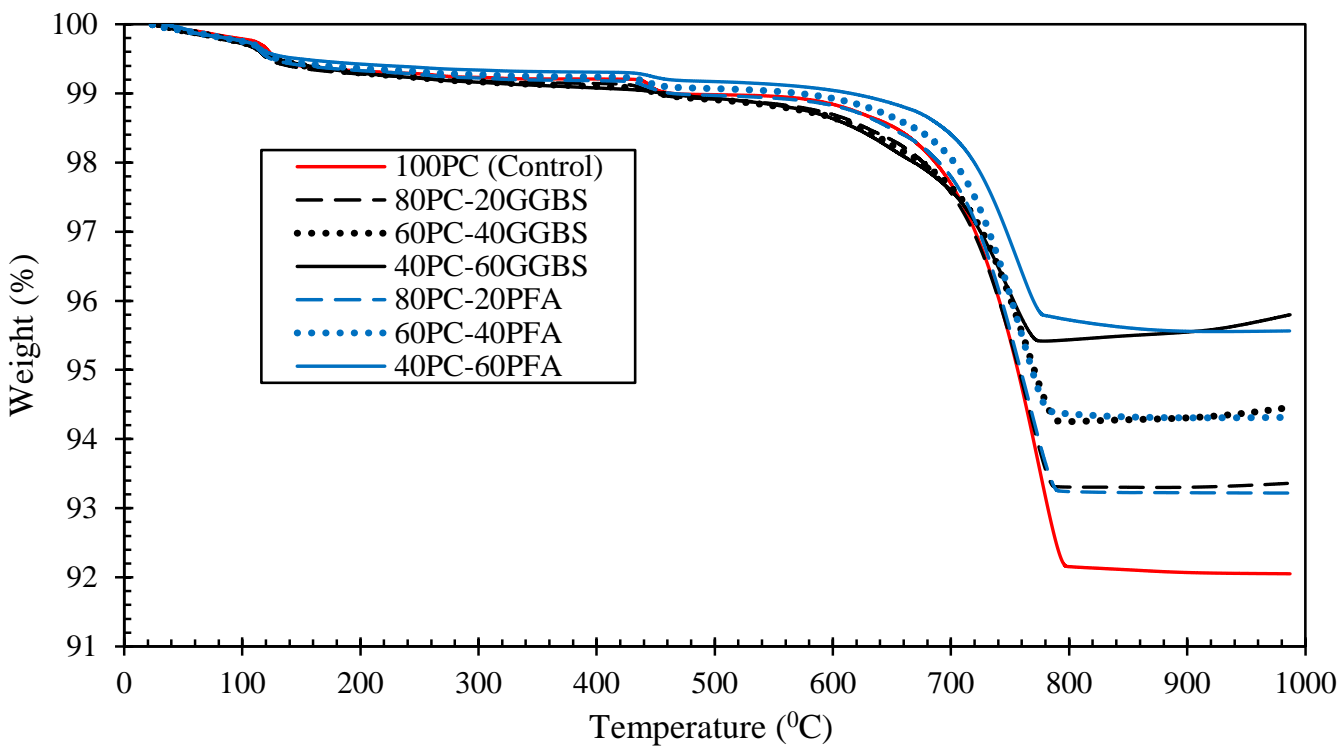

Figure 2. TG analysis results for all mixes

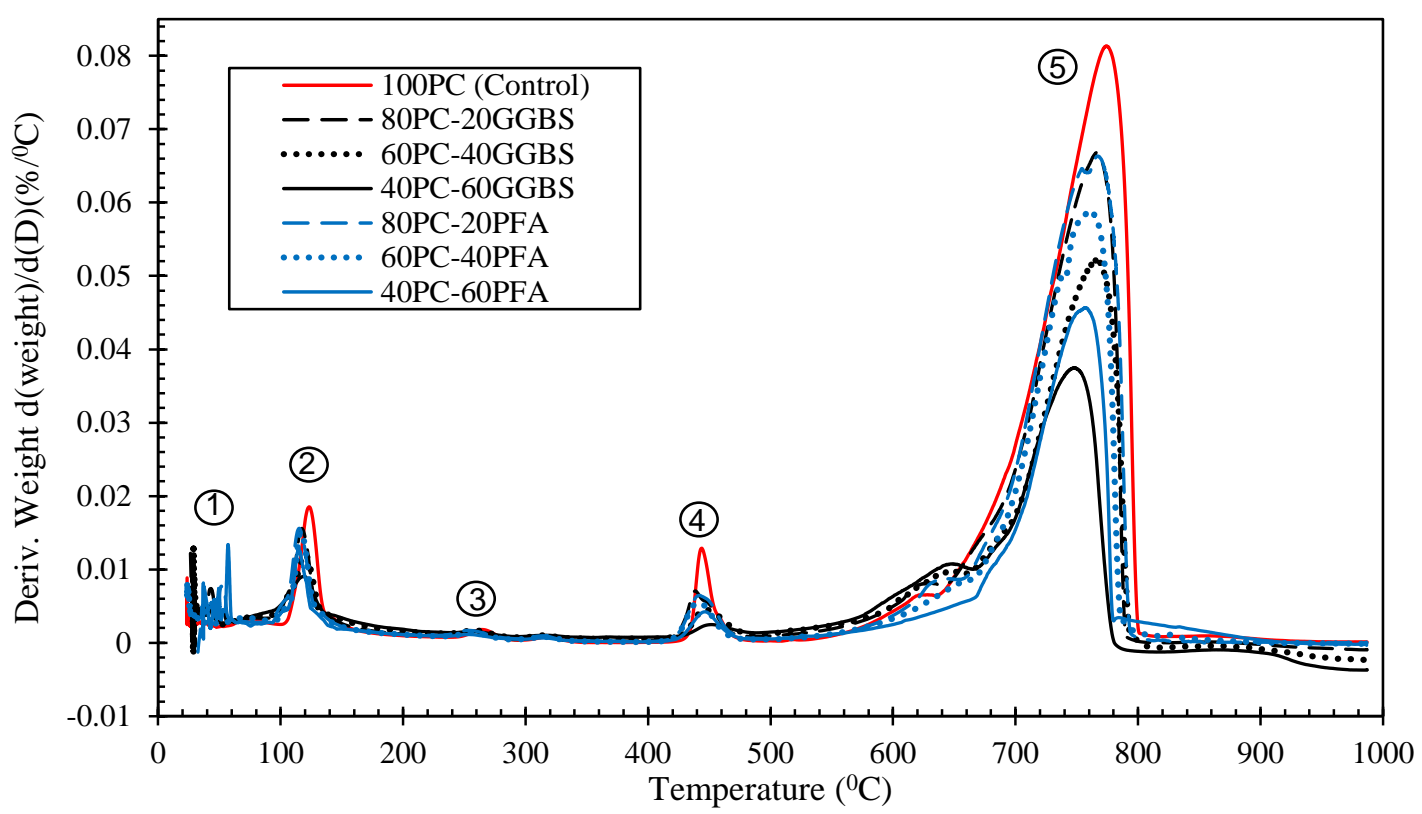

Figure 3. DTG analysis results for all mixes

The identified peak at points 4 was reported by Alonso and Fernandez [23] as the decomposition of the calcium hydroxide (portlandite) present within each mix, due to the use of PC with significant calcium content for the activation of cementitious materials (GGBS and PFA) in each mix composition. A further decomposition of calcium within each mix composition to form calcium carbonate (Calcite) was evident at peak 5 which is in line with the findings of Song, Jeong [24], who suggested a range of $650-900^{\circ} \mathrm{C}$ for complete decomposition of calcium to form calcium carbonate. Observations suggest that the control mix has a large influence on the TG/DTG curves (see Figures 2 and 3). This could be due to the inert (glassy/amorphous) nature of GGBS and PFA (see Figure 1), which readily reacts with the control mix containing100\% quantity of PC.

Observations also show that there is a corresponding weight-loss for every endothermic DTG peak developed (see Figures 2 and 3). Figure 4 shows the variations in the weight-loss obtained for all the mixes after thermal analysis. The weight-losses obtained showed that Mix 1(Control) attained the highest weight loss of 7.9\%, while mix D4 achieved the lowest weight-loss of 4.4\%. The improved thermal performance of the mix with 40PC60GGBS could be due to the high amount of GGBS within the mix blend, which is likely to result in strong and compact crystalline bonding compared with PFA and PC. 


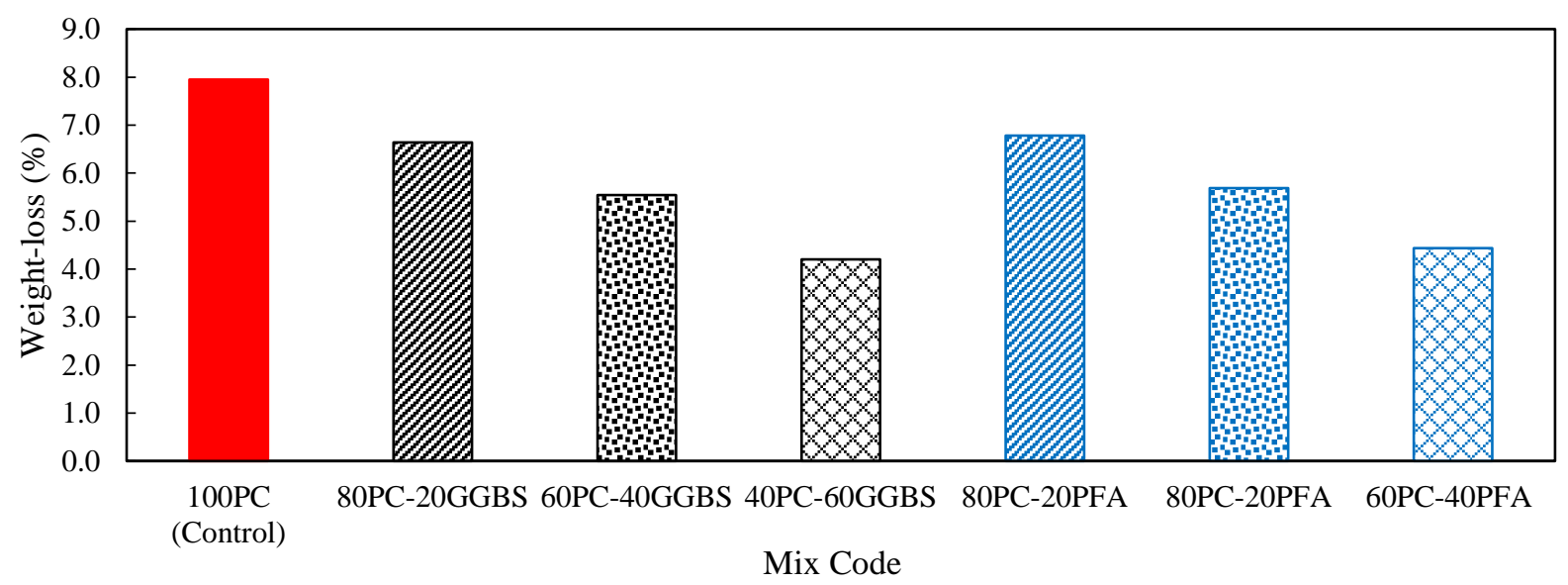

Figure 4. Total weight-loss (\%) due to thermal process for all mixes

\subsection{Consistency of fresh concrete}

The results for the consistency of the fresh concrete measured through the slump test are shown in Figure 5. The slump value observed for the control mix, 100PC, was 45mm. The design mixes 80PC-20GGBS, 60PC40GGBS, 40PC-60GGBS, 80PC-20PFA, 60PC-40PFA and 40PC-60PFA, show variations in slump values depending on the material used to partially replace the PC and the percentage of PC replaced. In the mixes where GGBS is used to replace the PC in the control mix, the concrete product with 20\% GGBS and $80 \%$ PC (mix 80PC20GGBS) recorded a higher slump value of 60mm but design mixes 60PC-40GGBS and 40PC-60GGBS recorded decreased slump values of $40 \mathrm{~mm}$ and $38 \mathrm{~mm}$ respectively. Although the slump values of design mixes 60PC40GGBS and 40PC-60GGBS (40mm and 38mm) were lower than mix 80PC-20GGBS, they were still relatively close to the observed slump value for the control mix.

The slump values of the concrete where the PC was replaced with PFA were all significantly higher than that of the control mix. The concrete design mix 60PC-40PFA recorded a higher slump value of 85mm. During the mixing of the concrete and whilst performing the slump tests, no segregation of concrete was observed in any of the concrete mixes.

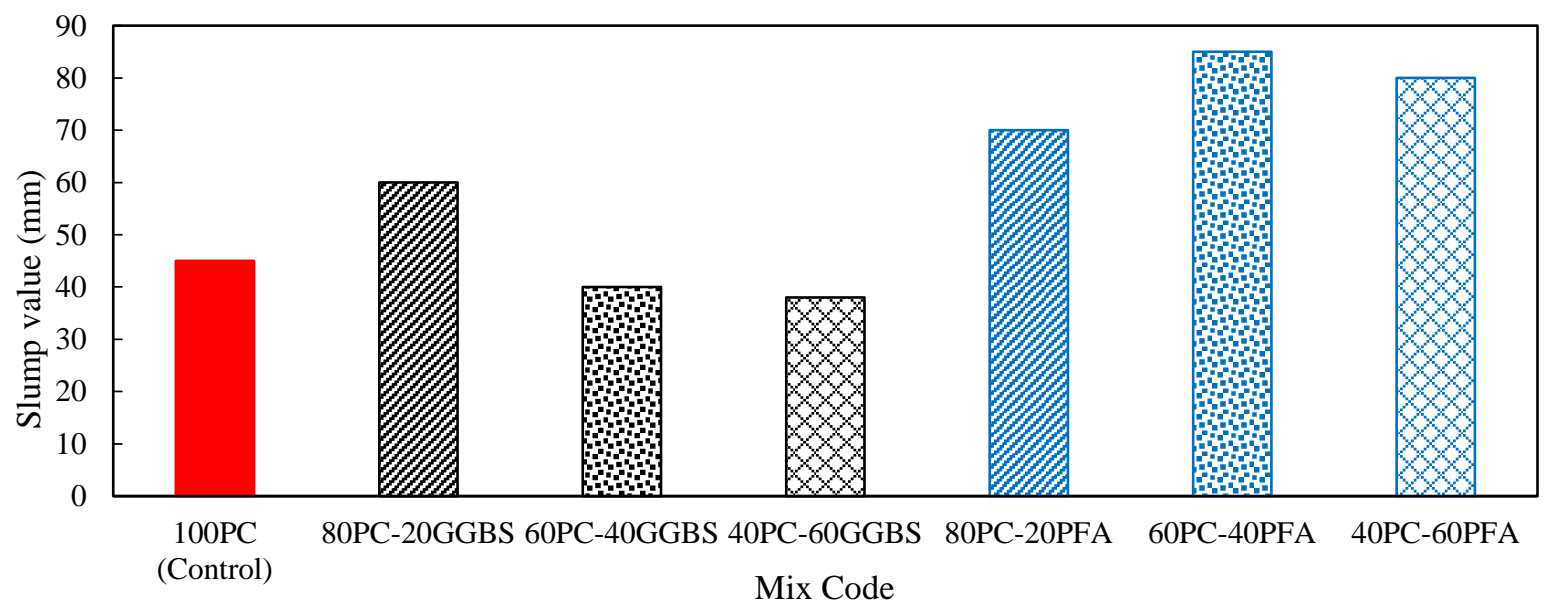

Figure 5. Slump value for all mixes

Figure 6 shows the results of the compaction index test. The observed compaction index value for the control mix was 1.22 . The design mixes where $20-6 \%$ of GGBS or PFA were used to replace the PC in the control mix, showed a variation in compaction index values depending on the material used to partially replace the PC and the percentage of replacement. The compaction index values observed, for the concrete mixes where GGBS was used as a partial PC replacement material, were all similar to the control mix, the highest compaction index values was obtained from mix 40PC-60GGBS. The observed compaction index values, for the concrete mixes where PFA was used as partial PC replacement material are all significantly lower than the compaction index value of the control mix. The lowest compaction index value was observed for mix 60PC-40PFA. 
Overall, the use of GGBS as a partial replacement for PC in concrete improved the workability of the concrete at 20\% PC replacement level, the reason for this was because the cementitious particles of GGBS were better dispersed at $20 \%$ replacement level. In addition, the surface of the particles of GGBS were smooth and absorb little water during mixing, producing a smoother, more fluid cement paste and thus producing a more workable concrete. Similarly, the use of PFA as a partial replacement material for PC in concrete improved the workability of the concrete at $40 \%$ PC replacement level. The increase in slump values with PFA addition may be attributed to the extremely spherical particle shape of PFA, which may act as miniature ball bearings within the concrete mix, thus providing a lubricant effect [25]. Using the PFA improved the consistency of the concrete, mixes flow more easily on site and so speed up the construction process, hence the concrete made with PFA, had lower compaction index values than concrete with GGBS, producing a greater fluidity to the concrete. Previous studies by Yijin, Shiqiong [26], Zhou, Slater [27] and Bhavana and Madhavi [28] and more recently Oti [25], showed that using PFA and GGBS as partial PC replacements in the cement paste increases the fluidity and workability of the concrete when compared to standard ordinary PC concrete.

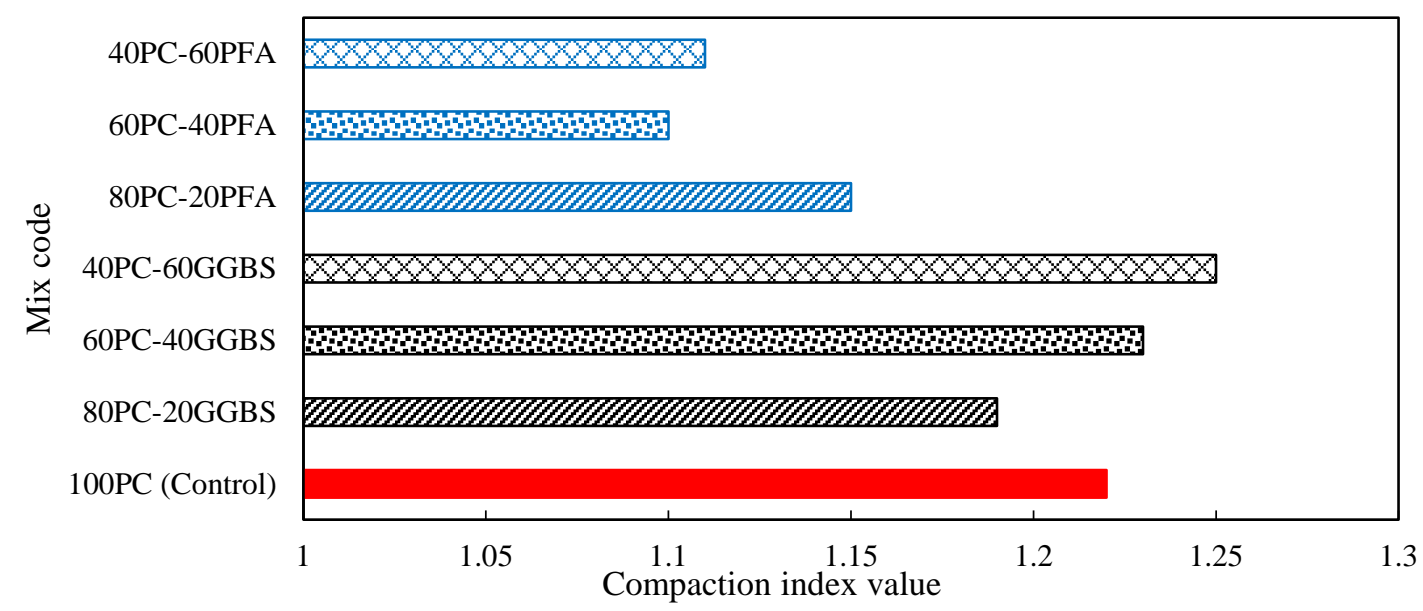

Figure 6. Compaction Index value for all mixes

\subsection{Compressive strength}

Figure 7 shows the compressive strength results for all concrete mixes at the curing age of 7, 28 and 56 days. It can be seen that the compressive strength for the control (100PC) achieved the highest initial compressive strength $\left(27.46 \mathrm{~N} / \mathrm{mm}^{2}\right)$ after 7 days curing across all the design mixes. This could be attributed to the high amount of tricalcium silicate $\left(\mathrm{C}_{3} \mathrm{~S}\right)$ present in PC, which is responsible for initial strength gain. The concrete where GGBS was used as PC replacement (mixes 80PC-20GGBS, 60PC-40GGBS and 40PC-60GGBS), showed slightly lower compressive strength values (92\%, 89\% and 78\% respectively) compared with the control mix at 7 days curing. Mix 60PC-40GGBS experienced a significant increase in compressive strength $\left(38.2 \mathrm{~N} / \mathrm{mm}^{2}\right)$ compared with the control at 28 days. The compressive strength of the control mix, after 56 days curing was marginally lower $\left(39.7 \mathrm{~N} / \mathrm{mm}^{2}\right)$ with mix 60PC-40GGBS and 80PC-20GGBS obtaining the highest compressive strength value of 42.1 and $40.4 \mathrm{~N} / \mathrm{mm}^{2}$ respectively. The reason is because compressive strength of concrete increase with age. Mix 80PC-20PFA produced the highest compressive strength (33.16, 33.2 and 37.1N/mm $\mathrm{m}^{2}$ respectively) after 7, 28 and 56 days curing compared with mixes 60PC-40PFA and 40PC-60PFA respectively with significantly lower compressive strength. However, concrete mixes incorporating PFA (mixes 80PC-20PFA, 60PC-40PFA and 40PC60PFA), had considerably lower compressive strength values at 7, 28 and 56 days of curing respectively, compared with the control mix and mixes with GGBS. Observation also showed a marginal reduction in compressive strength values for mix 40PC-60GGBS at 7days curing age compared with mixes with PFA, while concrete mixes with GGBS as PC replacement (mixes 80PC-20GGBS, 60PC-40GGBS and 40PC-60GGBS) produced high compressive strength values compared to all design mixes with PFA at both 28 and 56 days curing age.

Since the concretes made from mixes containing GGBS were able to achieve a minimum compressive strength of $30 \mathrm{~N} / \mathrm{mm}^{2}$ at 28 days, they are classified as concretes that are suitable for structural application. A maximum of $60 \%$ GGBS and 20\% PFA can be utilised to partially replace the PC in the concrete. The compressive strength of the control mix, after 56 days of curing was $39.7 \mathrm{~N} / \mathrm{mm}^{2}$, which again, was not the highest compressive strength achieved after 56 days of curing.

Overall, when up to $60 \%$ of PC was replaced with PFA, a significantly lower early age strengths was achieved, the decreasing values of early age compressive strength with the decreasing percentage of PC in the design mixes is likely due to the volume and quantity of the C-S-H gel formed from the hydrating blended binder. The gel primarily gives the cement paste the cohesion with the aggregates, bonding them together to form a strong mixture 
[29]. Every design mix where there is a reduction in PC in the binder, has higher water/binder ratios and therefore the more PC replaced, the wetter and weaker the mix becomes. This could be due to the reduction in $\mathrm{C}_{3} \mathrm{~S}$ required for the initial hydration (exothermic reaction) which absorbs high amounts of water. Although this is a negative effect for compressive strength, it is a positive effect for workability. GGBS and PFA, are slower reacting pozzolans and have slower hydration rates when compared to PC and therefore the early-age strengths are lower. The optimum percentage of partial PC replacement using GGBS is $40 \%$, although up to $60 \%$ could be used if early age strength isn't required. The results shown and discussed in this research suggests that GGBS can be used to partially replace up to $60 \%$ of PC in concrete agrees with the findings in studies by Suresh and Nagaraju [30]. It also suggests a maximum of $20 \%$ PFA replacement for PC in concrete as the 28-day and 56-day strengths provide adequate compressive strength for C30 concrete.

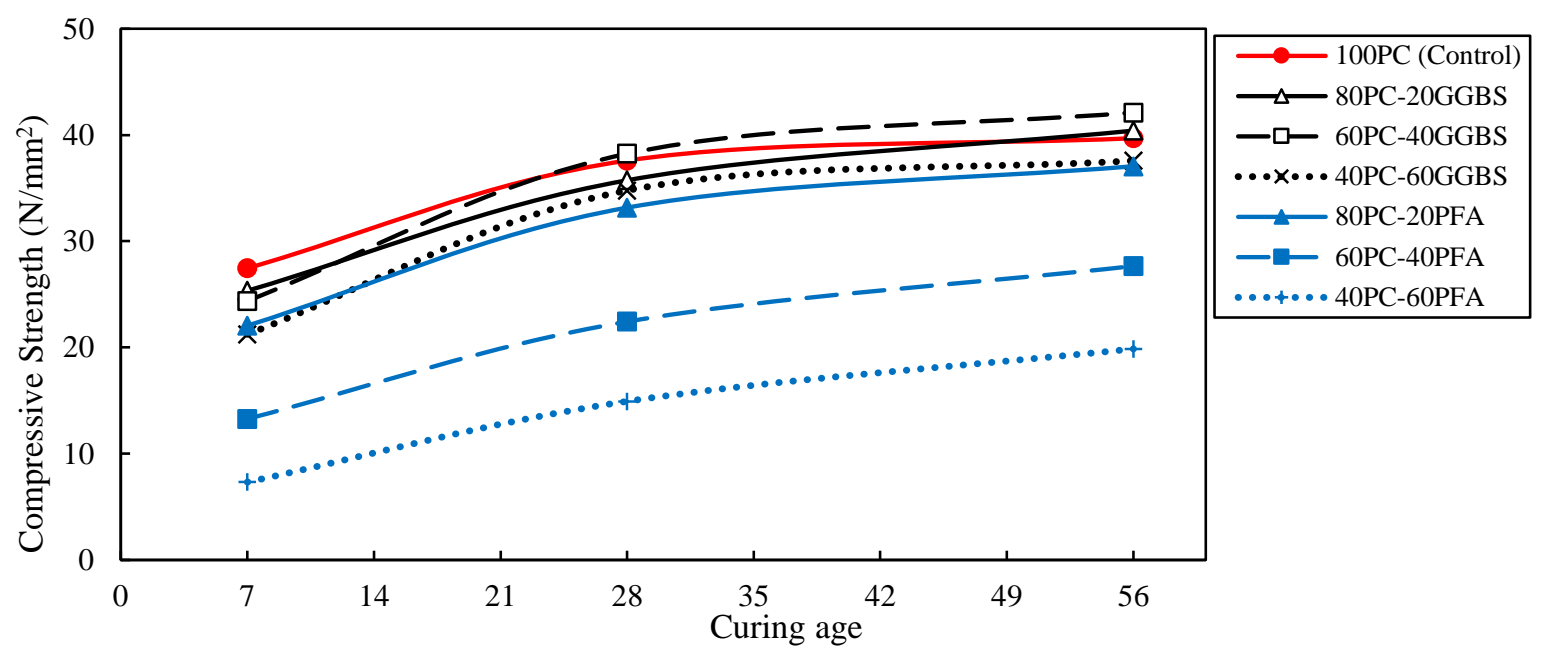

Figure 7. Compressive strength development of the various concrete design mixes

\subsection{Weight Gain/ Loss due to freezing and thawing}

A typical profile of freezing and thawing cycles indicating the percentage weight loss or gain is shown in Figure 8. It can be seen that the highest weight loss of $0.085 \%$ was experienced by the concrete mix with PFA (40PC60PFA), while mix 80PC-20GGBS containing GGBS attained the highest weight gain of $0.249 \%$. The observed weight loss within the ranges of $0.041-0.085 \%$ was evident within the $4^{\text {th }}-6^{\text {th }}$ cycles with no further weight loss at latter stages ( 7 and $8^{\text {th }}$ cycle) for all the concrete mixes including the control. Mixes with GGBS showed a marginal reduction in weight loss (0.041-0.042\%) compared to mixes with PFA with significant weight loss within the ranges of $0.042-0.085 \%$. There was no significant change in weight loss for the control mix when compared with mixes containing GGBS, but a significant increase of $0.044 \%$ in weight loss when compared with mixes made with PFA. The reduction in weight loss for mixes with $80-60 \%$ replacement of PC with GGBS is quite beneficial to the overall density of the produced concrete and the reduction in the loss of water of crystallization required for continuous hydration reaction [31].

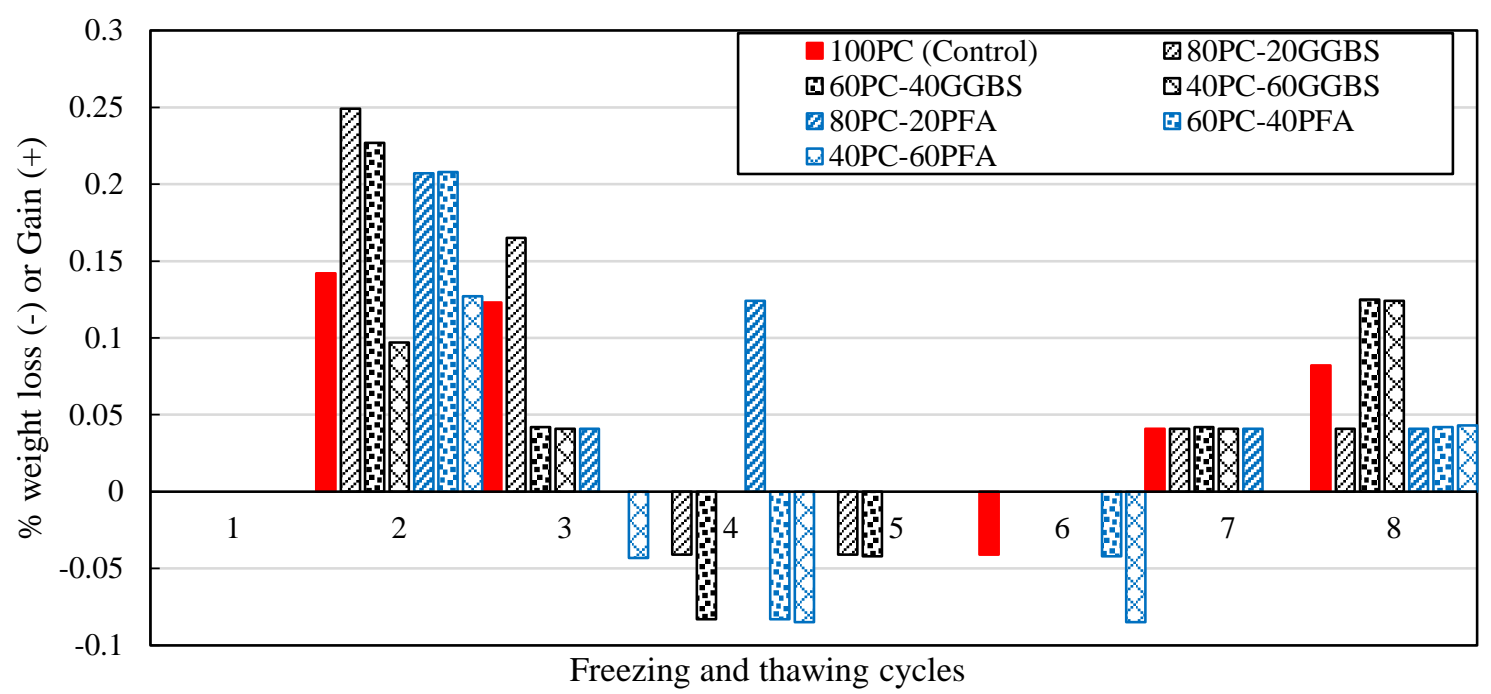

Figure 8. \% Weight loss or gain due to freezing and thawing over 56 days/ 8 Cycles 


\subsubsection{Visual inspection}

Table 3 shows the details of the defect/damages to the different concrete mixes through visual inspection after the freezing and thawing cycles. The control mix experienced a substantial amount of chips and scaling along all the edge and faces of the concrete cube specimens (more than $1 \mathrm{~mm}$ lost) when compared to all the other concrete mix specimens with GGBS and PFA respectively. Mix 80PC:20GGBS and 80PC:20PFA experienced minimal chipping and minor scaling of the concrete face (less than $0.5 \mathrm{~mm}$ ) compared to all other mixes. Previous studies by Pigeon and Regourd [32] and Virtanen [33], reported that increased amounts of GGBS in concrete can cause increased amounts of scaling. It was also observed that the intensity of scaling and peeling of the surfaces of the concrete cubes across all the mixes are more prominent with the mixes containing PFA compared to GGBS. This could be due to the increased reactivity of GGBS as a latent hydraulic material for increased hydration reaction.

\subsubsection{Strength Gain/ Loss}

The concrete specimens that were subjected to weekly freeze and thaw cycles also underwent compressive strength testing at 7, 28 and 56 days to determine the compressive strength gained or lost (see Figure 9). A general trend of loss in compressive strength was observed across all the concrete specimens during the curing period of 7, 28 and 56 days. Mixes 60PC-40PFA and 40PC-60GGBS obtained the lowest (16.1\%) and highest (73.3\%) loss in compressive strength at 7 and 28 days respectively. It can also be observed that concrete specimens with GGBS experienced higher compressive strength loss compared with the obtained compressive strength of PFA at 7 and 28 days, but later reduced the strength loss within the ranges of 39.5 to $54.5 \%$ compared with the mixes made from PFA (39.1 - 62.5\%) at 56 days curing period. This same trend can be seen for the loss in compressive strength of the control compared with other concrete specimens made from GGBS and PFA, which indicates an initial increase in loss in compressive strength of $20.3 \%$ and $39.5 \%$ at 7 and 28 days respectively, but later reduced to $28.8 \%$ after 56 days. The general trend of compressive strength loss can be attributed to the freezing of the water in the concrete which slows down the hydration reaction to produce less amount calcium silicate hydrate (C-S-H) gel necessary for strength gain in the concrete. The reduction in loss of compressive strength for concrete specimens made from GGBS compared with PFA can also be attributed to the increased hydration reaction at altering stages due to the pozzolanic effect GGBS possesses over PFA as a latent hydraulic material for increased hydration reaction while PFA is just a filler within the concrete mix [34].

Table 3. Visual Inspection of Damage at the End of the Freeze and Thaw Cycles

\begin{tabular}{|c|c|}
\hline Description of Damage & Visual Remarks \\
\hline Fractures & $\begin{array}{l}\text { No fractures were observed at the end of the } 8^{\text {th }} \text { freeze and thaw cycle for all } \\
\text { the concrete specimens under investigation }\end{array}$ \\
\hline Scaling/ Peeling & $\begin{array}{l}\text { Minimal scaling was observed on all the faces of the design mixes } \\
\text { 80PC:20GGBS and 80PC:20PFA after all the freeze and thaw cycles were } \\
\text { completed. Design mixes 60PC:40PFA and 40PC:60PFA had minor scaling on } \\
\text { all faces and design mixes 60PC:40GGBS and 40PC:60GGBS had medium } \\
\text { scaling on all faces during the freeze and thaw cycles. Prominent scaling was } \\
\text { observed on the control mix during the freeze and thaw cycles. }\end{array}$ \\
\hline Hairline Cracks $<0.2 \mathrm{~mm}$ & $\begin{array}{l}\text { No hairline cracks were observed on any of the concrete specimens during the } \\
\text { freezing and thawing cycles. }\end{array}$ \\
\hline Surface Crack $>0.2 \mathrm{~mm}$ & $\begin{array}{l}\text { During the entire freezing and thawing process, up to } 8 \text { cycles, no surface } \\
\text { cracks were observed on any of the concrete specimens. }\end{array}$ \\
\hline Chipping & $\begin{array}{l}\text { Chipping mainly occurred along the edges of all the concrete specimens during } \\
\text { the freeze and thaw cycles. Design mixes 80PC:20GGBS and 60PC:40GGBS } \\
\text { only had minor chipping along all the edges, whereas the control mix and } \\
\text { design mixes 60PC:40PFA and 40PC:60PFA had prominent chippings along } \\
\text { all edges. Design mixes 40PC:60GGBS and 80PC:20PFA had minor chippings } \\
\text { along all edges during the freeze and thaw cycles. }\end{array}$ \\
\hline Craters & $\begin{array}{l}\text { No craters were observed in any of the concrete specimens after the } 8^{\text {th }} \text { freezing } \\
\text { and thawing cycle. }\end{array}$ \\
\hline $\begin{array}{l}\text { Major Spalling/ } \\
\text { Delamination }\end{array}$ & $\begin{array}{l}\text { No major spalling or delamination occurred on any of the concrete specimens } \\
\text { throughout all the freezing and thawing cycles. }\end{array}$ \\
\hline
\end{tabular}




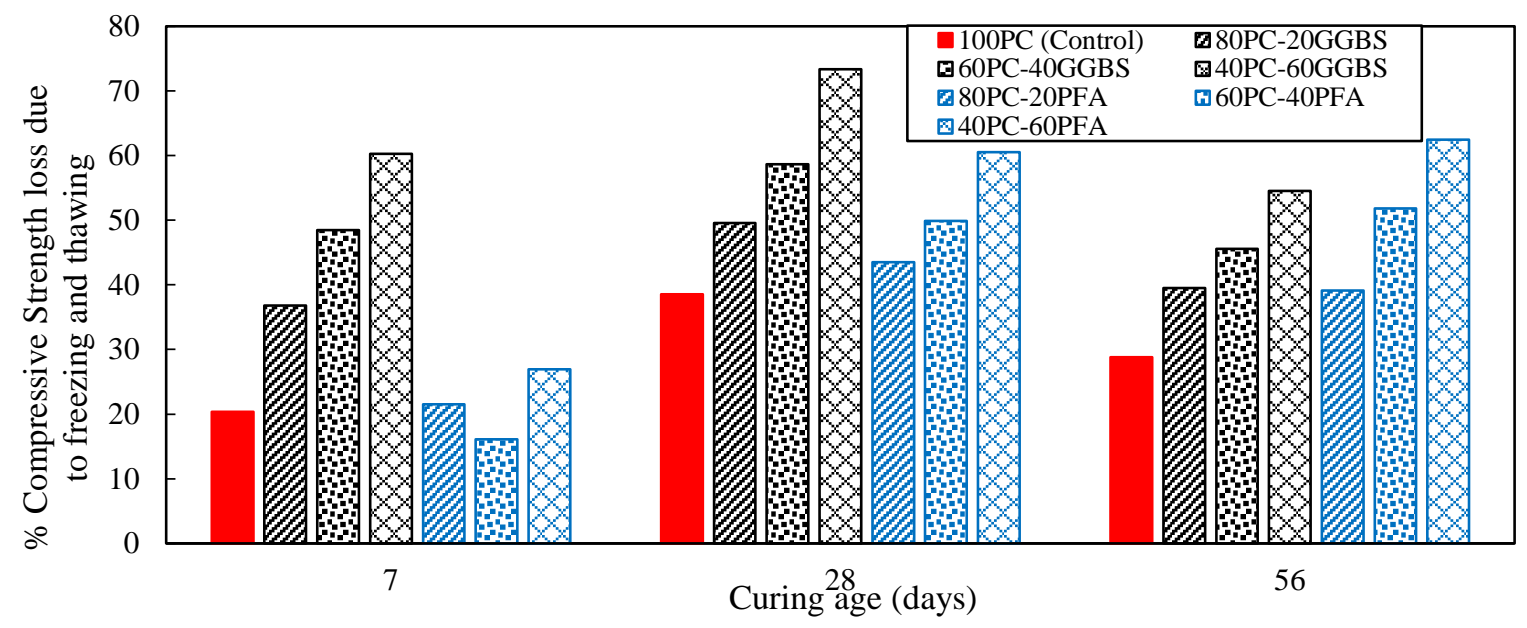

Figure 9. \% Compressive Strength Loss due to Freezing and Thawing

\section{Conclusions}

The results obtained in this work suggests there is potential in the use of PFA and GGBS as partial PC replacement in concrete for a variety of improved engineering properties. This will reduce the environmental impact caused by the manufacture of PC and will lead to the use of more sustainable concrete in the construction industry. The following conclusions can be drawn from this research:

1) The variations within the mix binders after thermal analysis indicates a continuous reduction in weight-loss (4 -7\%) for every increase in percentage replacement of GGBS and PFA with 8\% weight-loss for PC. This is as a result of the strong and compact crystalline bonds GGBS and PFA possess compared with PC, which suggests the use of industrial by-products (GGBS and PFA) for concrete applications.

2) Although the consistency of the fresh concrete mixes varies, the slump values and compaction index values obtained suggest that the concrete became more workable when GGBS or PFA were used to partially replace PC in the control mix. The workability of the concrete increases with the increase in percentage of PFA replacing PC, with $40 \%$ replacement being the optimum for the most workable concrete. Whereas when GGBS replaced PC, the workability only increased when $20 \%$ was replaced.

3) The compressive strength of the concrete after 56 days curing varied for the different concrete design mixes with concrete mixes made of $40 \%$ replacement of GGBS achieved the highest strength. The concrete mixes made by using GGBS as PC replacement achieved significantly better compressive strengths after 56 days compared with that of PFA, with up to 40\% GGBS achieving higher compressive strength than the control. 20 - $60 \%$ replacement of GGBS with PC can be suggested for structural applications with strengths from 30N/mm². Concrete mixes with PFA replacing PC in the control, resulted in decreasing compressive strengths relative to the percentage increase of PFA. Although they were weaker than the control, a maximum of $20 \%$ PFA can be suggested as a partial replacement due to achieving a $30 \mathrm{~N} / \mathrm{mm}^{2}$ strength.

4) The durability of concrete subject to freeze and thaw had little effect on the concrete specimens. It was observed that the control mix suffered the worst, resulting in minimal scaling of the faces and chipping along the edges of the concrete cubes. All concrete mixes suffered strength loss at 7, 28 and 56 days testing compared to the concrete specimens that were not subject to freeze and thaw. The control mix suffered the least strength loss. Strength loss increased as the percentages of GGBS and PFA increased for each mix. Overall, concrete mixes with GGBS possessed more durability potential compared with PFA at later stages of curing (56 days).

\section{References}

[1] WBCSD. World business council for sustainable development: $\mathrm{CO}_{2}$ and climate protection. 2015.

[2] Liew KM, Sojobi AO, Zhang LW. Green concrete: Prospects and challenges. Construction and Building Materials. 2017;156:1063-1095.

[3] Jin R, Chen Q. An investigation of current status of "green” concrete in the construction industry. In: 49th ASC Annual International Conference Proceedings. San Luis Obispo, CA.,USA. 2013.

[4] Wesseling JH, Van der Vooren A. Lock-in of mature innovation systems: the transformation toward clean concrete in the Netherlands. Journal of Cleaner Production. 2017;155:114-124.

[5] Rafeet A, Vinai R, Soutsos M, Sha W. Guidelines for mix proportioning of fly ash/GGBS based alkali activated concretes. Construction and Building Materials. 2017;147:130-142. 
[6] Tavasoli S, Nili M, Serpoush B. Effect of GGBS on the frost resistance of self-consolidating concrete. Construction and Building Materials. 2018;165:717-722.

[7] Bondar D, Basheer M, Nanukuttan S. Suitability of alkali activated slag/fly ash (AA-GGBS/FA) concretes for chloride environments: Characterisation based on mix design and compliance testing. Construction and Building Materials. 2019;216:612-621.

[8] BS EN 450-1. Fly ash for concrete-, in Part 1: Definition, specifications and conformity criteria. 2012

[9] BS EN 15167-1. Ground granulated blast furnace slag for use in concrete, mortar and grout. Part 1: Definitions, specifications and conformity criteria. 2006.

[10] BS EN 197-1.Cement. Part 1: Composition, specifications and conformity criteria for common cements. 2011.

[11] BS EN 12620:2002+A1. Aggregates for concrete. 2008.

[12] Oti JE, Kinuthia JM. Engineering properties of concrete made with brick dust waste. In:9th International Concrete Conference. 2016. p. 70-77.

[13] Standard test method for thermal stability by thermogravimetry. In: Annual Book of ASTM Standards. ASTM E2550 - 17. ASTM International: West Conshohocken, PA. 2010.

[14] BS EN 206:2013+A1. Concrete - Specification, performance, production and conformity. 2016.

[15] BS EN 12350-2. Testing fresh concrete. Part 2: Slump test. 2019

[16] BS EN 12350-4. Testing fresh concrete, in Part 4: Degree of compactability. 2019.

[17] BS EN 12390-3. Testing hardened concrete, in Part 3: Compressive strength of test specimens. 2019.

[18] BS EN 12390-6. Testing hardened concrete, in Part 6: Tensile splitting strength of test specimens. 2009

[19] PD CEN/TS 12390-9. Testing hardened concrete. Part 9: Freeze-thaw resistance with de-icing salts — Scaling. 2016

[20] Scrivener K, Snellings R, Lothenbach B. A practical guide to microstructural analysis of cementitious materials. 1st ed. Danvers. USA: Taylor \& Francis Group; 2016.

[21] Sonat C, Unluer C. Investigation of the performance and thermal decomposition of $\mathrm{MgO}$ and $\mathrm{MgO}-\mathrm{SiO} 2$ formulations. Thermochimica Acta. 2017;655:251-261.

[22] Collier NC. Transition and decomposition temperatures of cement phases-a collection of thermal analysis data. Ceramics-Silikaty. 2016;60(4): 338-343.

[23] Alonso C, Fernandez L. Dehydration and rehydration processes of cement paste exposed to high temperature environments. Journal of Materials Science. 2004;39(9):3015-3024.

[24] Song H, Jeong Y, Bae S, Jun Y, Yoon S, Oh JE. A study of thermal decomposition of phases in cementitious systems using HT-XRD and TG. Construction and Building Materials. 2018;169:648-661.

[25] Oti J. Engineering properties of concrete made with pulverised fly ash. International Journal of Mechanical and Production Engineering. 2018; 6(3): 60-63.

[26] Yijin L, Shiqiong Z, Jian Y, Yingli G. The effect of fly ash on the fluidity of cement paste, mortar, and concrete. In:Proceedings of the International Workshop on Sustainable Development and Concrete Technology. 2004. p. 339-345.

[27] Zhou XM, Slater JR, Wavell SE, Oladiran O. Effects of PFA and GGBS on early-ages engineering properties of Portland cement systems. Journal of Advanced Concrete Technology. 2012;10(2):74-85.

[28] Bhavana TD, Madhavi E. Strength and workability properties of concrete replaced by quarry dust and GGBS. International Journal of Engineering Research \& Technology. 2016;5(03): 23-27.

[29] VitroMinerals. VCASTM White Pozzolans. 2016. http://www.vitrominerals.com/products/recycled-glasspowders/vcas-white pozzolans/concrete-chemistry/.

[30] Suresh D, Nagaraju K. Ground granulated blast slag (GGBS) in concrete-a review. IOSR Journal of Mechanical and Civil Engineering. 2015;12(4):76-82.

[31] Oti JE, Kinuthia JM, Bai J. Engineering properties of unfired clay masonry bricks. Engineering Geology. 2009;107(3-4):130-139.

[32] Pigeon M, Regourd M. Freezing and thawing durability of three cements with various granulated blast furnace slag contents. In: Fly Ash, Silica Fume and Slag in Concrete. 1983, SP-79: American Concrete Institute, USA. p. 979-998.

[33] Virtanen J. Freeze-thaw resistance of concrete containing blast furnace slag, fly ash or condensed silica fume. In: First International Conference on the Use of Fly Ash, Silica Fume, Slag and Other Mineral By-products in Concrete. ACI SP-79, Montebello, Canada. 1983.

[34] Behnood A. Soil and clay stabilization with calcium-and non-calcium-based additives: A state-of-the-art review of challenges, approaches and techniques. Transportation Geotechnics. 2018;17:14-32.

(C) 2020 by the author(s). This work is licensed under a Creative Commons Attribution 4.0 International License (http://creativecommons.org/licenses/by/4.0/). Authors retain copyright of their work, with first publication rights granted to Tech Reviews Ltd. 